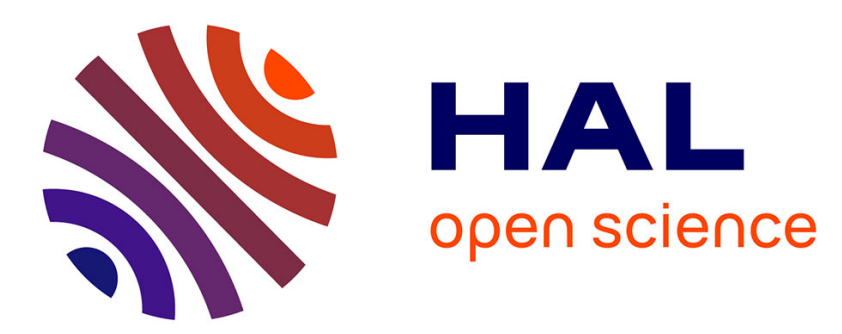

\title{
Amorphization of $\beta$-thorium phosphate diphosphate $(\beta$-TPD) irradiated with high energy krypton ions
}

C. Tamain, F. Garrido, L. Thomé, N. Dacheux, A. Özgümüs, A. Benyagoub

\section{To cite this version:}

C. Tamain, F. Garrido, L. Thomé, N. Dacheux, A. Özgümüs, et al.. Amorphization of $\beta$-thorium phosphate diphosphate $(\beta$-TPD) irradiated with high energy krypton ions. Journal of Nuclear Materials, 2006, 357, pp.206-212. 10.1016/j.jnucmat.2006.06.008 . in2p3-00107026

HAL Id: in2p3-00107026

https://hal.in2p3.fr/in2p3-00107026

Submitted on 17 Oct 2006

HAL is a multi-disciplinary open access archive for the deposit and dissemination of scientific research documents, whether they are published or not. The documents may come from teaching and research institutions in France or abroad, or from public or private research centers.
L'archive ouverte pluridisciplinaire HAL, est destinée au dépôt et à la diffusion de documents scientifiques de niveau recherche, publiés ou non, émanant des établissements d'enseignement et de recherche français ou étrangers, des laboratoires publics ou privés. 


\title{
Amorphization of $\beta$-Thorium Phosphate Diphosphate ( $\beta$-TPD) irradiated with high energy krypton ions
}

\author{
C. Tamain ${ }^{\mathrm{a}}$, F. Garrido ${ }^{\mathrm{b}, *}$, L. Thoméb ${ }^{\mathrm{b}}$, N. Dacheux ${ }^{\mathrm{a}}$, A. Özgümüs ${ }^{\mathrm{a}}$, A. Benyagoub ${ }^{\mathrm{c}}$ \\ ${ }^{a}$ Groupe de Radiochimie, Institut de Physique Nucléaire, CNRS-IN2P3-Université Paris-Sud \\ 11, Bâtiment 100, F-91406 Orsay Campus. \\ ${ }^{\mathrm{b}}$ Centre de Spectrométrie Nucléaire et de Spectrométrie de Masse, CNRS-IN2P3-Université \\ Paris-Sud, Bâtiment 108, F-91405 Orsay Campus. \\ ${ }^{c}$ Centre Interdisciplinaire de Recherche Ions Lasers, Rue Claude Bloch, BP 5133, F-14070 \\ Caen cedex 5.
}

\begin{abstract}
As potential actinide-bearing phase for geological deposit of nuclear wastes, the $\beta$-Thorium Phosphate Diphosphate ceramic $\left(\beta\right.$-TPD), $\mathrm{Th}_{4}\left(\mathrm{PO}_{4}\right)_{4} \mathrm{P}_{2} \mathrm{O}_{7}$, must be resistant against radiation. A high-energy ion beam $(840-\mathrm{MeV} \mathrm{Kr})$ was used to check this property by simulating the electronic effects of radiation. The amorphization of the material was followed in situ by using the on line XRD analysis setup (CHEXPIR) of the GANIL accelerator. XRD measurements show a complete amorphization of the material with a kinetics which fits to a direct impact model. Thermal annealing of amorphized samples leads to a complete recrystallization of the structure at $1023 \mathrm{~K}$.
\end{abstract}

* Corresponding author. Tel. +33 1691552 57, E-mail address: garrido@csnsm.in2p3.fr 


\section{Introduction}

Ceramics, especially phosphated ones, are presented as good candidates for nuclear waste immobilization [1-3]. Thorium Phosphate-Diphosphate ( $\beta$-TPD), $\beta-\mathrm{Th}_{4}\left(\mathrm{PO}_{4}\right)_{4} \mathrm{P}_{2} \mathrm{O}_{7}$, has been proposed as an actinide-bearing phase for nuclear waste storage. This material, which can be loaded in situ with large amounts of tetravalent actinides [4,5], appears to be very resistant against aqueous corrosion [6] and exhibits a good thermal stability.

A good candidate for nuclear waste immobilization must also be resistant to radiation. Actually, a nuclear waste matrice is subjected to the $\alpha$-decay of incorporated actinide elements, which produces typically $5-\mathrm{MeV} \alpha$-particles and heavy recoil nuclei of about 100 $\mathrm{keV}$. The kinetic energy of an incident particle in a solid can be transferred either to electrons by ionization or electronic excitations or to atoms by ballistic processes involving elastic collisions. In $\alpha$-decays, the nuclear contribution is dominant for low-energy recoil nuclei $(\sim 100 \mathrm{keV})$, while the transfer is mainly electronic for the high-energy $\alpha$-particle $(\sim 5-\mathrm{MeV})$. It is well-known that ion irradiation can deeply modify the crystalline structure of a solid and consequently alter its physical and chemical properties, such as the chemical durability of the irradiated zones [7]. Therefore it is of major interest to study the production of radiation defects in a storage matrix in both electronic and nuclear regimes.

The most worrisome radiation effect affecting nuclear matrices is certainly the transformation of the crystalline phase into an amorphous one. Many studies have been previously devoted to the amorphization trend of phosphate-based ceramics selected for nuclear waste storage. Karioris et al. [8] irradiated monazite $\left(\mathrm{LnPO}_{4}\right)$ with 3-MeV $\mathrm{Kr}$ at room

temperature and found that this material amorphizes at a fluence less than $5 \times 10^{14} \mathrm{~cm}^{-2}$. According to Meldrum et al. [9], phosphate ceramics should present a lower sensibility to ionbeam irradiation than silicate analogue structures. However, radiation effects have never been 
investigated on $\beta$-TPD. It was necessary to submit this material to drastic irradiation conditions in order to determine the limit resistance to amorphization.

This article presents a study of the damage resulting from the irradiation of $\beta$-TPD with $840-\mathrm{MeV}$ krypton ions. In storage conditions, the energy of both $\alpha$-particles and recoil nuclei is much lower (see above). However, the high energy of krypton ions was chosen with the double aim to $(i)$ alter the material on a thickness which is observable by in situ XRD analyses and (ii) investigate the effects of almost pure electronic energy loss. The study of the radiation damage created by elastic collisions via the use of low-energy ion beams is the topic of a forthcoming work.

\section{Experimental procedures}

\subsection{Synthesis of the samples}

$\beta$-TPD can be synthesized through several ways [4]. For irradiation experiments, the samples were prepared by the wet chemical method [10] which involves the initial precipitation of the Thorium Phosphate Hydrogen Phosphate Hydrate (TPHPH), $\mathrm{Th}_{2}\left(\mathrm{PO}_{4}\right)_{2} \mathrm{HPO}_{4} \cdot \mathrm{H}_{2} \mathrm{O}$, as a crystallized precursor. A mixture of concentrated thorium nitrate and phosphoric acid solutions (respectively of $5 \times 10^{-4}$ mol.g $\mathrm{g}^{-1}$ i.e. $0.7 \mathrm{M}$ and $4 \times 10^{-3} \mathrm{~mol} \mathrm{~g}^{-1}$ i.e. $5 \mathrm{M}$ ), considering a mole ratio of $r=\mathrm{PO}_{4} / \mathrm{Th}=3 / 2$, was slowly evaporated at $433 \mathrm{~K}$ for 8 10 days in a PTFE container. The crystallized solids were separated from the supernatant by centrifugation at $4000 \mathrm{rpm}$. They were washed several times with deionized water in order to eliminate the remaining acid and then with ethanol. They were finally dried at $363 \mathrm{~K}$ for 2-3 hours.

The obtained TPHPH powder was characterized by X-Ray diffraction (XRD), Electron Probe MicroAnalysis (EPMA) and Scanning Electron Microscopy (SEM). The 
surface area was estimated at $15 \mathrm{~m}^{2} \mathrm{~g}^{-1}$ from the B.E.T. method. These results match well with previous studies [11].

After heating at $723 \mathrm{~K}$ in air in order to eliminate volatile compounds, the obtained $\alpha$-TPD powder [12] was sintered via an uniaxial room temperature pressing at $250 \mathrm{MPa}$ in a $10 \mathrm{~mm}$ diameter cylindrical die. The resulting pellets were then thermally heated in an alumina crucible for 15 hours at $1473-1523 \mathrm{~K}$ to prepare $\beta$-TPD. The sintering enables to increase the cohesion of the grains in the solid and leads to a compound with an enhanced mechanical resistance. The dimensions of the pellets after sintering are $8.8 \mathrm{~mm}$ in diameter and $0.9 \mathrm{~mm}$ in thickness.

\subsection{Irradiations and X-Ray Diffraction analysis}

Ion irradiations were performed with $840-\mathrm{MeV}^{78} \mathrm{Kr}^{32+}$ ions at room temperature on the CHEXPIR setup at the GANIL accelerator (Caen, France). This facility enables to follow in situ the structural evolution of irradiated materials by means of an INEL XRD apparatus equipped with a CPS 120 detector. The XRD patterns were recorded at room temperature from 10 to $60^{\circ}(2 \theta)$ using a monochromatized $\mathrm{CuK}_{\alpha}$ radiation $(\lambda=0.15418 \mathrm{~nm})$. The ion flux was about $5 \times 10^{8} \mathrm{~cm}^{-2} \mathrm{~s}^{-1}$, which led to an increase of temperature lower than $100 \mathrm{~K}$. Thus thermal annealing under irradiation was negligible and could not compete significantly with amorphization. XRD acquisitions were performed at several fluences in the range $10^{11}-10^{13}$ $\mathrm{cm}^{-2}$ in order to follow the evolution of the crystalline structure of $\beta$-TPD under irradiation. As the pellet got activated under irradiation, it was necessary to let the activity decrease for at least 15 minutes after each irradiation run before performing the XRD acquisition in order to limit the background.

The electronic $\left(S_{\mathrm{e}}\right)$ and nuclear $\left(S_{\mathrm{n}}\right)$ contributions to the $\mathrm{Kr}$ ion energy loss were determined with the Monte Carlo simulation TRIM 2000 code [13] assuming a density of 
$5.2 \mathrm{~g} \mathrm{~cm}^{-3}$ and a threshold energy of $25 \mathrm{eV}$ for all atoms [14]. The variations of $S_{\mathrm{e}}$ and $S_{\mathrm{n}}$ versus depth for $840-\mathrm{MeV} \mathrm{Kr}$ ions in $\beta$-TPD are reported in Fig. 1. The projected range $R \mathrm{p}$ and the range straggling $\Delta R \mathrm{p}$ of incident ions are about $72 \mu \mathrm{m}$ and $0.79 \mu \mathrm{m}$, respectively. The maximum X-ray penetration in $\beta$-TPD is about $9 \mu \mathrm{m}$, which corresponds to the first $12 \%$ of the range. Consequently, the characterization by XRD analysis only concerns an irradiated thickness where $S_{\mathrm{e}}$ can be considered as constant and equal to $1.03 \times 10^{4} \mathrm{keV}_{\mu \mathrm{m}^{-1}}$. In this

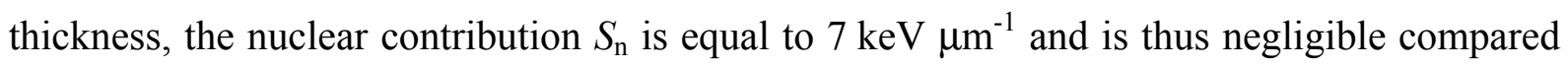
to $S_{\mathrm{e}}$. Actually, $S_{\mathrm{n}}$ leads to a dose of $10^{-4} \mathrm{dpa}$ (for the maximum fluence of $10^{13} \mathrm{~cm}^{-2}$ investigated in this study) which is well below the critical amorphization dose of 0.2 dpa determined in previous studies [15]. Thus irradiation-induced defects in the thickness probed by XRD are mainly created by electronic processes.

\subsection{Annealing experiments}

Annealing experiments of fully amorphized $\beta$-TPD pellets were made in alumina boats using Pyrox HM 40 or Adamel FR 20 furnaces. Samples were heated under air at $1023 \mathrm{~K}$. After each hour of heating XRD diagrams were registered in order to track recrystallization. They were collected with a Brücker D8 Advanced Roentgen diffractometer system using $\mathrm{CuK}_{\alpha}$ rays.

\section{Results and discussion}

Fig. 2 presents XRD diagrams recorded before and after irradiation at several ion fluences. Patterns exhibit a decrease of the amplitude of the main peaks as the fluence increases. A more detailed analysis of these diagrams in a reduced angular field (between $16.5^{\circ}$ and $17.2^{\circ}$ ) shows the effect of irradiation on the intensity of the XRD lines 
corresponding to the (020) reticular plane of $\beta$-TPD (Fig. 3). These figures underline the decrease of the net area and the increase of the full-width at half-maximum (FWHM) of the diffraction lines. This observation evidences the progressive amorphization of $\beta$-TPD by $\mathrm{Kr}$ ions. Amorphization of the whole irradiated thickness occurs at about $10^{13} \mathrm{~cm}^{-2}$.

The classical method of analysis of FWHM values uses the Williamson relation which enables to estimate the value of the constraints and the size of the coherent fields [16]:

$$
\delta(2 \theta) \cos \theta \approx \frac{k ?}{t}+4 \varepsilon \sin \theta
$$

where $k$ is the form factor which lies between 0.9 et $1, \lambda$ is the X-ray wavelength, $\tau$ is the mean diameter of coherence fields, $\theta$ is the diffraction angle, $\varepsilon$ is the squared average of the relative deformation of the interreticular distance, and $\delta(2 \theta)$ is the width corresponding to the material. The size of coherent fields was calculated according to Eq. 1 and was found to be about $1 \mu \mathrm{m}$. Thus Eq. 1 was used out of its field of validity.

The net area of the diffraction lines depends on the relative proportion of the amorphous phase in the crystalline structure according to the equation [17]:

$$
f_{a}=1-\frac{\sum_{i=1}^{n} \frac{A_{i}^{\text {irradiated }}}{A_{i}^{\text {unirradiated }}}}{n}
$$

where $A_{i}^{\text {irradiated }}$ is the net area of the diffraction line number $i$ in the XRD diagram recorded on the irradiated sample, $A_{i}^{\text {unirradiated }}$ is the net area of the same diffraction line in the XRD diagram on the unirradiated sample and $n$ is the number of diffraction lines considered.

The amorphization build-up may be followed by measuring the normalized area of the 26 main XRD lines in the XRD diagrams (Fig. 4). Experimental data may be modeled assuming that amorphization occurs via a direct ion impact mechanism [18], represented by the equation: 


$$
f_{a}=1-\exp \left(-\sigma_{a} \Phi\right)
$$

where $f_{a}$ is the amorphous fraction, $\Phi$ is the ion fluence and $\sigma_{a}$ is the cross-section of the cylinder around the ion path in which the matter is amorphized. The fit of experimental data to Eq. 3 allows one to extract the cross-section for radiation damage formation, $\sigma_{a}=(5.0 \pm$ $0.7) \times 10^{-13} \mathrm{~cm}^{2}$, which corresponds to a track diameter of $8.0 \pm 0.5 \mathrm{~nm}$.

The unit cell parameters and volume of the material under irradiation were estimated by fitting the XRD spectra with the U-Fit software [19]. This analysis was possible for fluences lower than $5 \times 10^{12} \mathrm{~cm}^{-2}$, i.e. when the diffraction lines are still well defined. Although the precision of the fit is not very high because of the broadening of the diffraction lines upon irradiation, the unit cell parameters decrease with increasing irradiation fluence (Fig. 5). The relative decrease is estimated to $1 \%$ between the unirradiated material and the fluence of $5 \times 10^{12} \mathrm{~cm}^{-2}$ in the three spatial directions: this leads to a decrease of the unit cell volume of $\approx 3 \%$. The similar decrease of the three unit cell parameters $a, b$ and $c$ shows the isotropy of the deformation due to amorphization. This interpretation is coherent with the similar evolution of the areas of the different diffraction lines of XRD spectra during irradiation (Fig. 6). Amorphization does not alter preferentially any crystallographic plan family.

This observation of a decrease of the cell volume is quite unusual for irradiated materials: it is far more common to observe a swelling of the unit cell in the first steps of amorphization. An exception is provided by silica which exhibits a densification under irradiation, due to the shift of the $\mathrm{SiO}_{4}$ tetrahedral groups from their initial crystallographic positions [20]. In the case of $\beta$-TPD, the same phenomenon may occur with the phosphate or diphosphate groups which may be displaced without being destroyed. This interpretation is supported by results obtained from $\mu$-Raman spectroscopy (Fig. 7). Indeed, the spectra recorded on irradiated samples always display the vibration bands characteristic of either 
phosphate or diphosphate groups even after complete amorphization (i.e. at a fluence of $10^{13}$ $\mathrm{cm}^{-2}$ ) (Table 1). Some spectra also present an increasing base line: this is due to the luminescence of the material under laser excitation, due to the presence of crystalline defects induced by irradiation. But the phosphate groups remain unchanged.

According to Scanning Electron Microscopy observations (Fig. 8), grain boundaries are less visible as irradiation progresses. This microstructure evolution may be due to the vitrification phenomenon observed in other irradiation experiments [15] and leads to a progressive disappearing of grain boundaries.

Annealing experiments were performed on fully amorphized $\beta$-TPD samples by heating them at $1023 \mathrm{~K}$ for 13 hours under air (Fig. 9). At the end of the annealing process, XRD spectra revealed a total recrystallization of the amorphous layer. The evolution during the thermal treatment of the net areas of the diffraction line for the different crystallographic planes is presented in Fig. 10. A similar increase of the areas of the various diffraction lines evidenced that the recrystallization process is isotropic (as amorphization). Furthermore, additional experiments showed that, at $900 \mathrm{~K}$, the annealing kinetics is very low: more than 1000 hours are required to reach complete recrystallization. This observation confirms the absence of annealing process under irradiation.

\section{Conclusion}

This study aimed to follow in situ the structural evolution of the phosphate-based ceramic $\beta$-TPD during irradiation with high-energy ion beams by using the CHEXPIR setup of the GANIL accelerator. Amorphization was achieved upon irradiation with $840-\mathrm{MeV}$ ions at room temperature. The exploitation of the XRD diffraction line areas enabled to estimate 
the amorphous fraction of the material as a function of the ion fluence. The variation of the amorphous fraction fits perfectly to the direct impact model, which leads to an estimation of the diameter of the ion track: $8.0 \pm 0.5 \mathrm{~nm}$. Total amorphization occurs in the whole thickness of the material at a fluence of $10^{13} \mathrm{~cm}^{-2}$. An isotropic compaction of the pellets is also observed under irradiation: the unit cell volume decreases by about $3 \%$ with the same kinetics in the three dimensions. Furthermore, no preferential alteration of any crystallographic plane family is observed. This phenomenon can be explained by a displacement of phosphate and diphosphate groups $\left(\mathrm{PO}_{4}\right.$ and $\left.\mathrm{P}_{2} \mathrm{O}_{7}\right)$ from their initial crystallographic positions without being altered. The presence of chemical bounds characteristic of phosphate groups in the amorphized material was confirmed by $\mu$-Raman spectroscopy. Total recrystallization was achieved upon thermal heating at $1023 \mathrm{~K}$.

This work was mainly devoted to the study of the effects of radiation on the structure of $\beta$-TPD. The irradiated samples were then submitted to dissolution tests in order to study the consequences of irradiation on the chemical properties of the material, more particularly the chemical durability of the irradiated phase. These results will be presented in a forthcoming paper [15].

\section{Acknowledgements}

This work was financially and scientifically supported by the french research program NOMADE (GDR 2023). The authors are grateful to the CIRIL staff for scientific help during the irradiation experiment. The authors would also like to thank Alain Kolher from the LCSM from Université Henri Poincaré Nancy-I (France) for performing the SEM observations, and Thérèse Lhomme from CREGU from Université Henri Poincaré Nancy-I for performing $\mu$ Raman analyses. 


\section{Table captions}

Table 1: Attribution of $\mu$-Raman bands $\left(\mathrm{cm}^{-1}\right)$ for unirradiated and irradiated $\beta$-TPD samples at several $\mathrm{Kr}$ fluences. 
Table 1

\begin{tabular}{c|cccc|cc}
\hline & \multicolumn{4}{|c|}{ (P-O) } & \multicolumn{2}{c}{ (P-O-P) } \\
& $\delta_{\mathrm{s}}\left(\mathrm{cm}^{-1}\right)$ & $\delta_{\mathrm{as}}\left(\mathrm{cm}^{-1}\right)$ & $v_{\mathrm{s}}\left(\mathrm{cm}^{-1}\right)$ & $v_{\mathrm{as}}\left(\mathrm{cm}^{-1}\right)$ & $v_{\mathrm{s}}\left(\mathrm{cm}^{-1}\right)$ & $v_{\mathrm{as}}\left(\mathrm{cm}^{-1}\right)$ \\
\hline Unirradiated $\beta-T P D$ & $350-450$ & $490-645$ & 960 & $970-1190$ & $700-740$ & $920-950$ \\
$10^{12} \mathrm{~cm}^{-2}$ & $350-450$ & $490-650$ & 950 & $970-1180$ & $700-740$ & $910-970$ \\
$7 \times 10^{12} \mathrm{~cm}^{-2}$ & $310-480$ & $490-660$ & N.O. & $970-1200$ & $680-800$ & N.O. \\
$2 \times 10^{13} \mathrm{~cm}^{-2}$ & $320-500$ & $450-650$ & N.O. & $900-1220$ & $680-820$ & N.O. \\
\hline
\end{tabular}




\section{Figure caption}

Figure 1. Variation of nuclear and electronic energy loss contributions versus depth in a $\beta$ TPD pellet irradiated with $840-\mathrm{MeV} \mathrm{Kr}$ ions.

Figure 2. XRD diagrams of sintered $\beta$-TPD pellet irradiated with $840-\mathrm{MeV} \mathrm{Kr}$ ions at several fluences.

Figure 3. Variation of the intensity of the XRD lines corresponding to the (020) reticular planes versus the $\mathrm{Kr}$ fluence.

Figure 4. Variation of the amorphous fraction with the Kr fluence. The solid line corresponds to a fit of data using equation (3).

Figure 5. Relative variations of the unit cell parameters $(\bullet: a, \mathbf{\Delta}: b, \mathbf{\square}: c)$ and of the cell volume $(\diamond)$ of $\beta$-TPD versus the $\mathrm{Kr}$ fluence.

Figure 6. Relative variations of the normalized areas of some XRD lines of $\beta$-TPD versus the irradiation fluence. $\mathrm{O}:(210), \bullet:(020), \mathbf{\square}:(212), \triangle:(421)$.

Figure 7. $\mu$-Raman spectra recorded on unirradiated and irradiated $\beta$-TPD sintered at the indicated fluences.

Figure 8. SEM micrographs of the surface of a $\beta$-TPD sintered sample before (a) and after irradiation with $840-\mathrm{MeV} \mathrm{Kr}$ ions at $2.5 \times 10^{12} \mathrm{~cm}^{-2}$ (b) and $10^{13} \mathrm{~cm}^{-2}$ (c).

Figure 9. XRD diagrams of an amorphous $\beta$-TPD sample during thermal annealing $(T=1023$ $\mathrm{K}$, one hour steps).

Figure 10. Relative variations of the normalized areas of some XRD lines of $\beta$-TPD versus

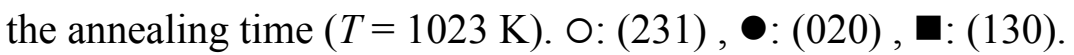




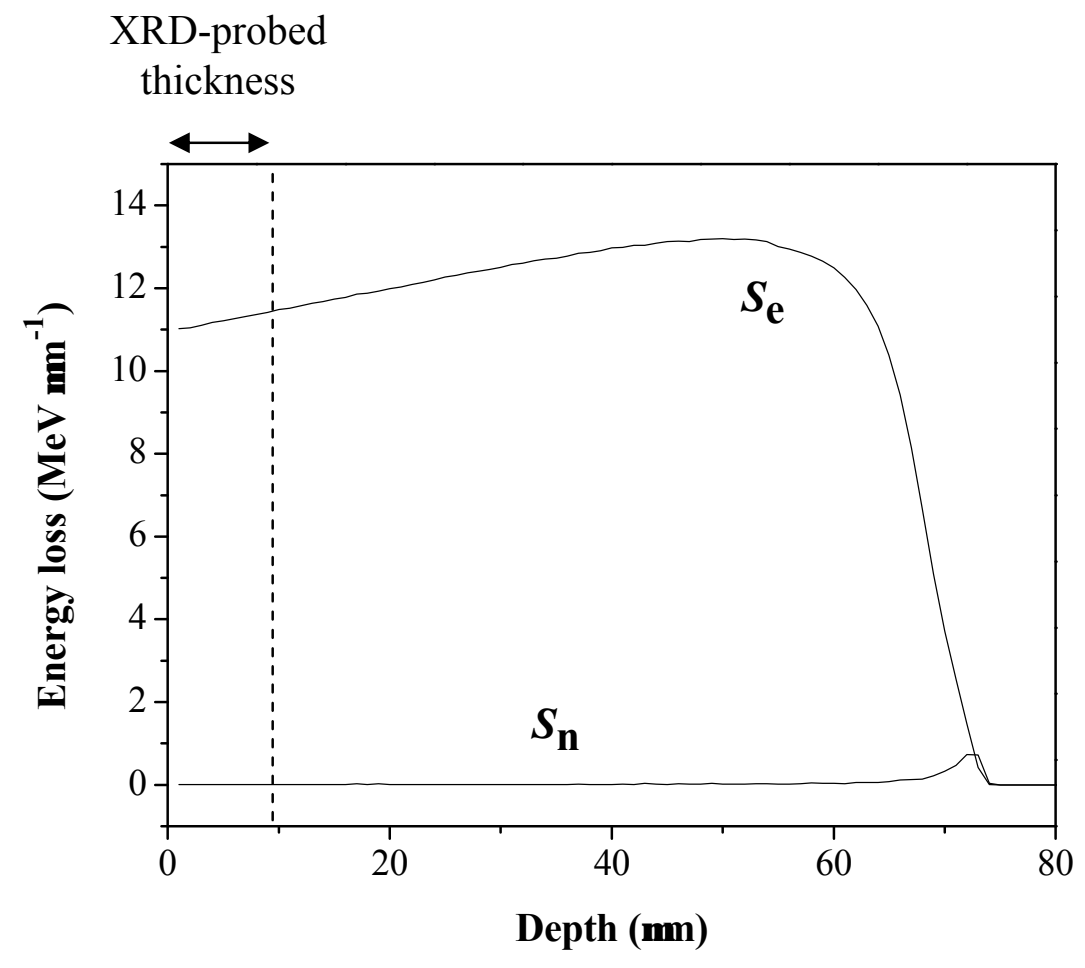

Fig. 1 


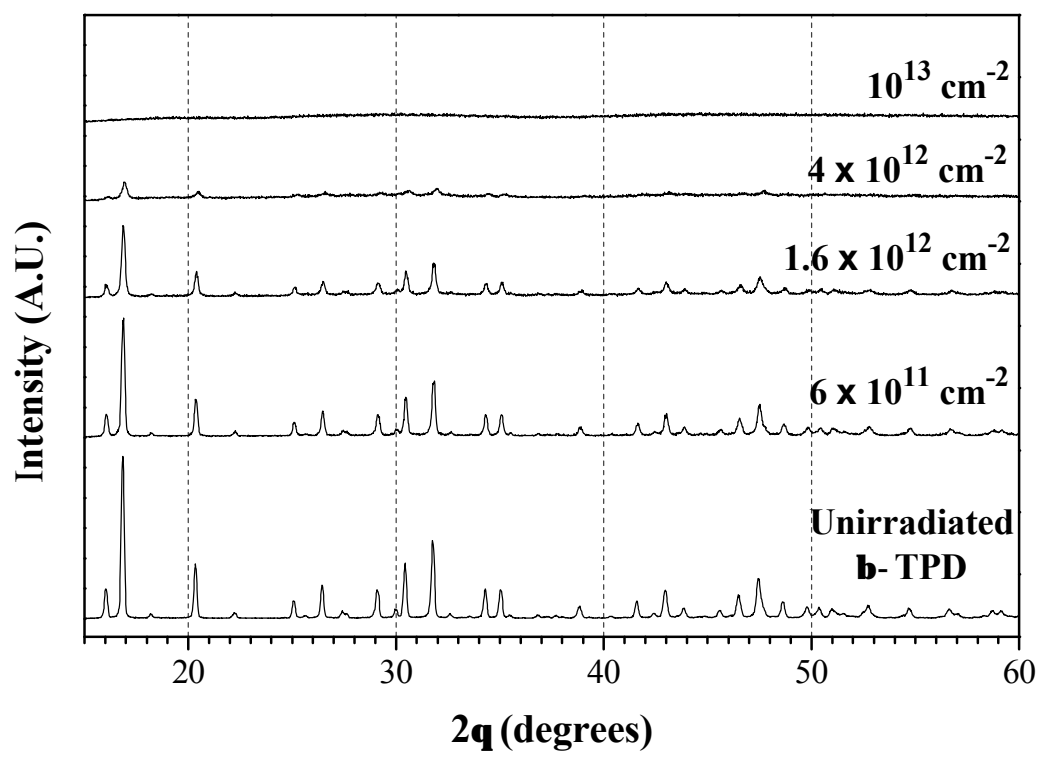

Fig. 2 


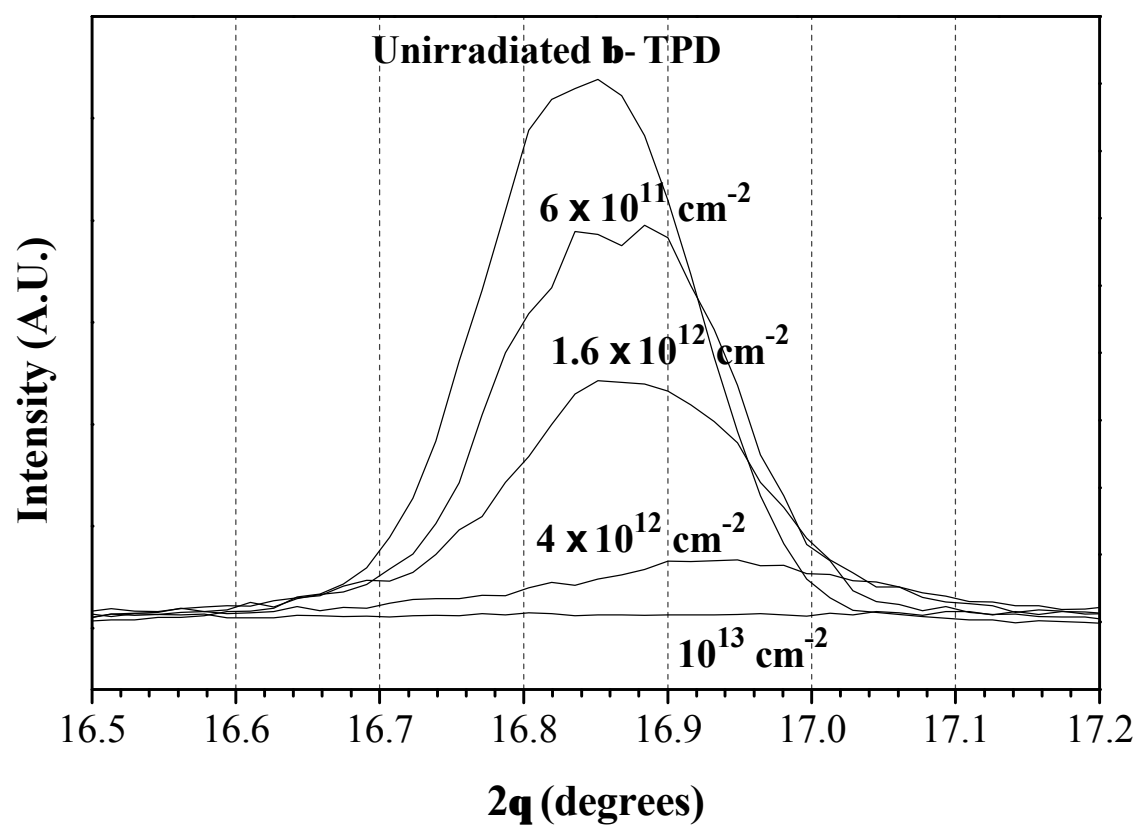

Fig. 3 


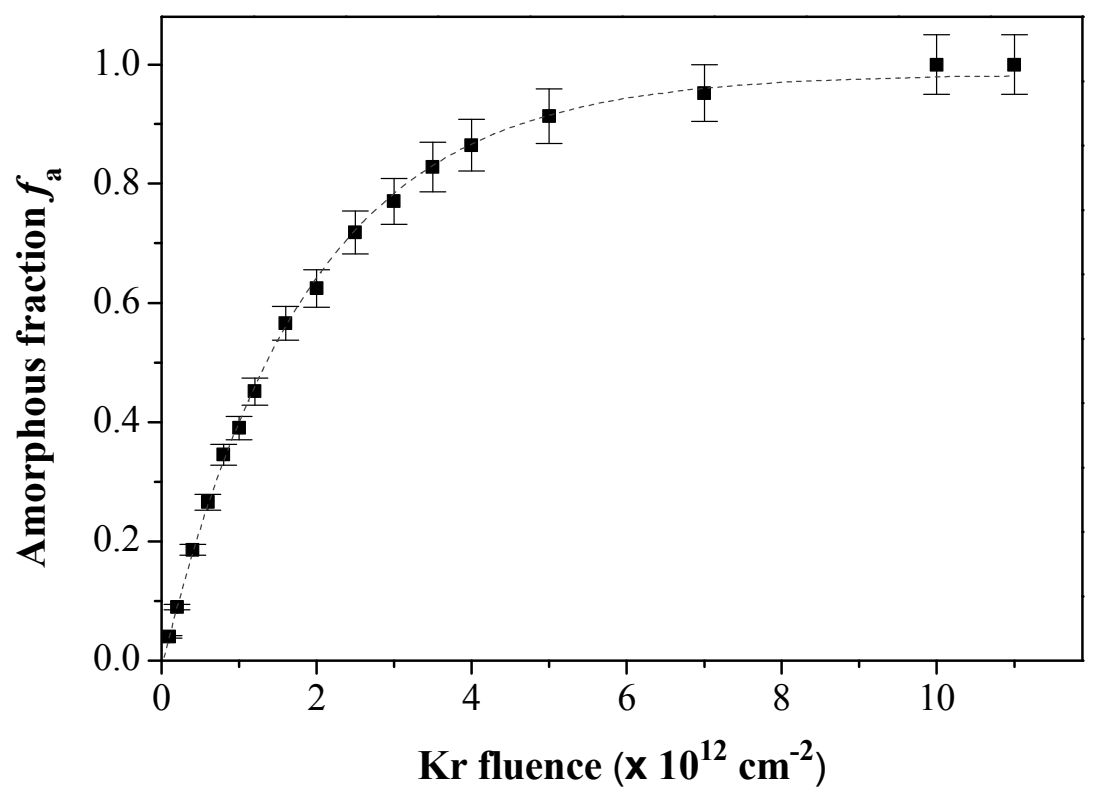

Fig. 4 


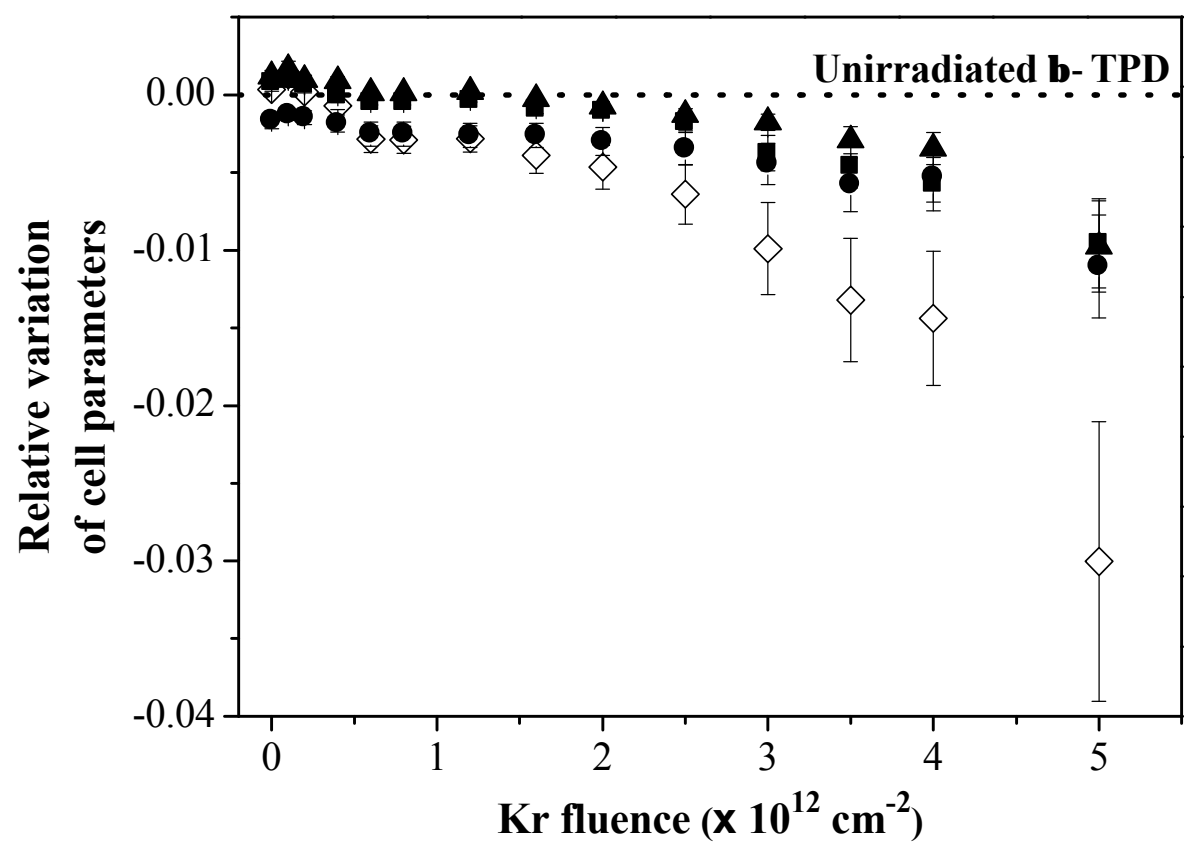

Fig. 5 


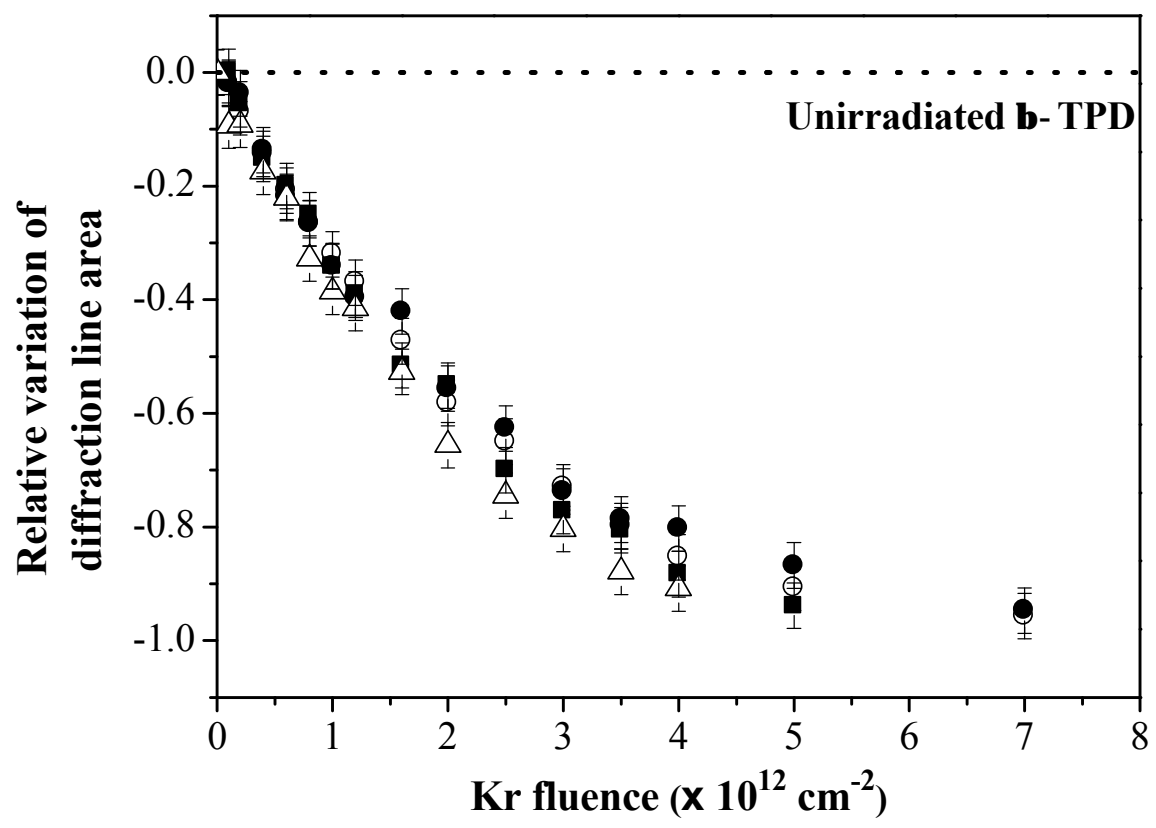

Fig. 6 


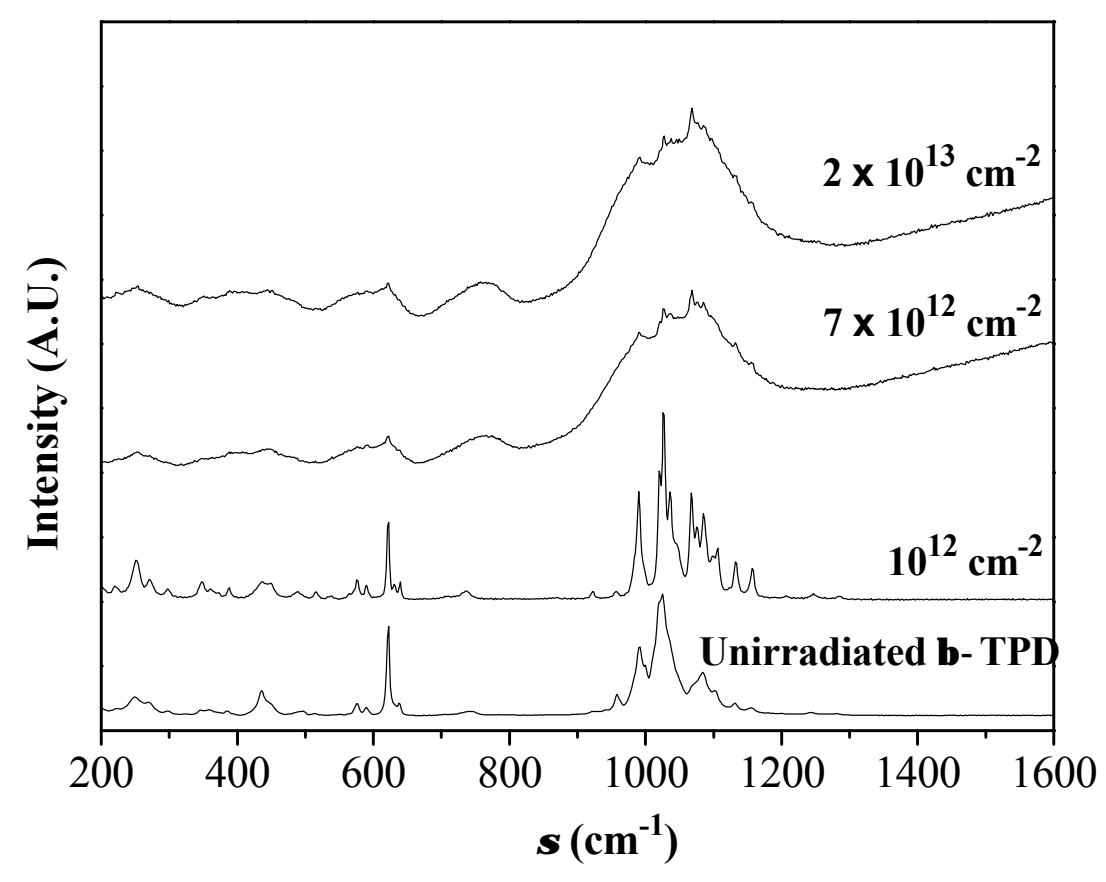

Fig. 7 


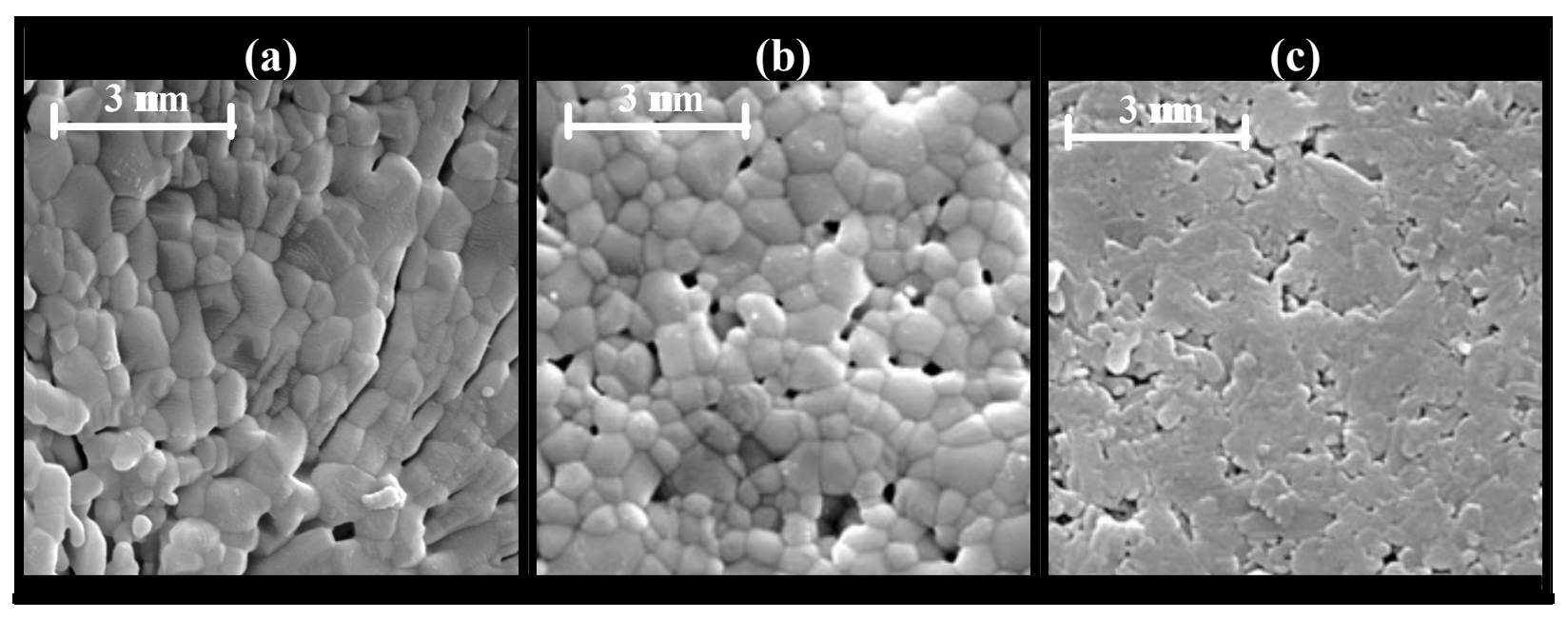

Fig. 8 


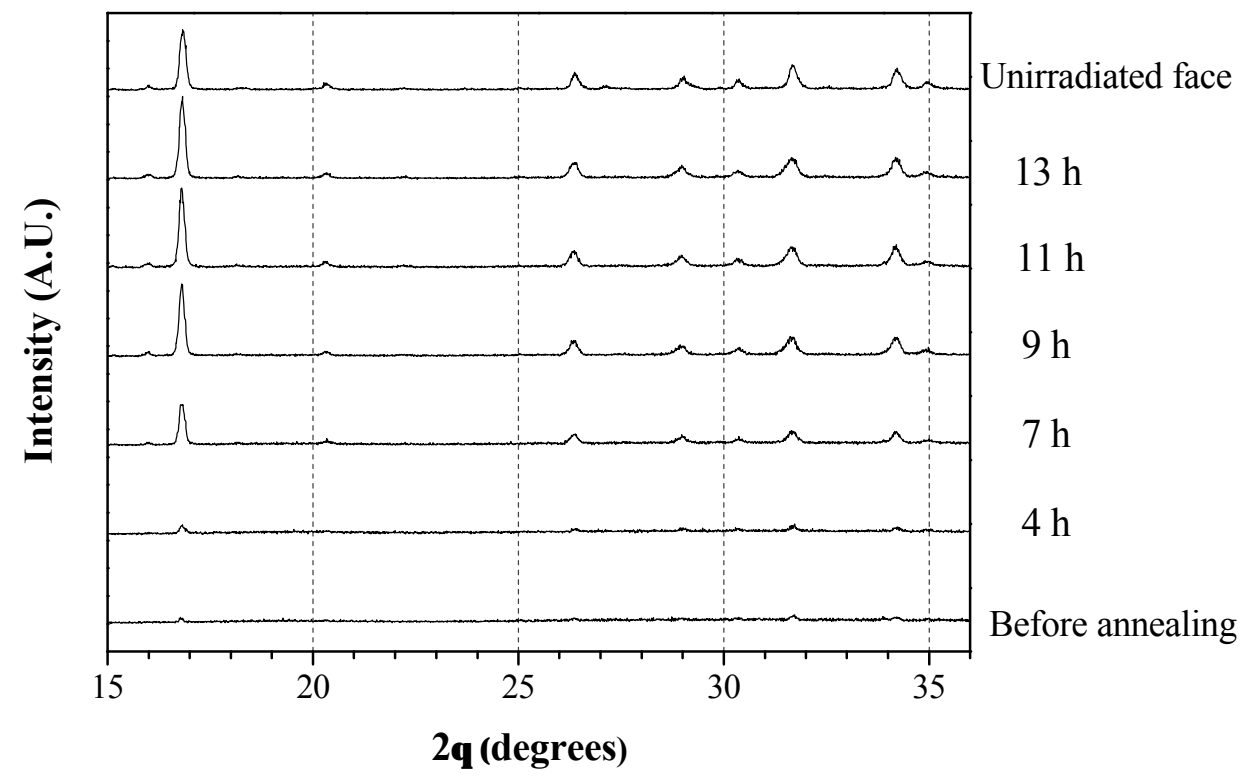

Fig. 9 


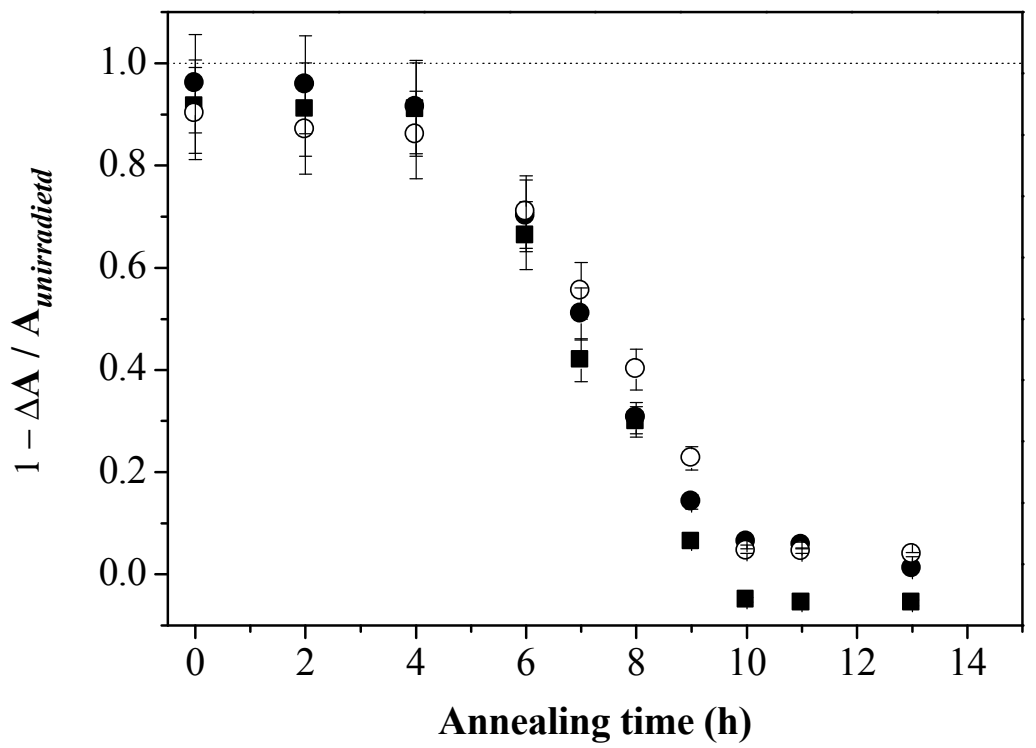

Fig. 10 


\section{References}

[1] V. Brandel, N. Dacheux, M ; Genet, J. Solid State Chem. 121 (1996) 467.

[2] V. Brandel, N. Dacheux, J. Solid State Chem. 177 (2004) 4743.

[3] V. Brandel, N. Dacheux, J. Solid State Chem. 177 (2004) 4755.

[4] P. Benard, V. Brandel, N. Dacheux, S. Jaulmes, S. Launay, C. Lindecker, M. Genet, D. Louër, M. Quarton, Chem. Mater. 8 (1996) 181.

[5] N. Dacheux, A.C. Thomas, V. Brandel, M. Genet, J. Nucl. Mater. 257 (1998) 108.

[6] A.C. Thomas, PhD thesis, Université-Paris-Sud-11, IPNO-T-00-09, 2000.

[7] W.J. Weber, R.C. Ewing, C.R.A. Catlow, T. Diaz De La Rubia, L.W. Hobbs, C. Kinoshita, H. Matzke, A.T. Motta, M. Natsai, E.K.H. Salje, E.R. Vance, S.J. Zinkle, J. Mater. Res. 13 (1998) 1434.

[8] F.G. Karioris, K. Appaji Gowda, L. Cartz, Radiat. Eff. Lett. 58 (1981) 1.

[9] A. Meldrum, L.A. Boatner, L.M. Wang, R.C. Ewing, Nucl. Instrum. And Meth. In Pys. Res. B 127 (1997) 160.

[10] N. Clavier, N. Dacheux, P. Martinez, V. Brandel, R. Podor, P. Le Coustumer, J. Nucl. Mater. 335 (2004) 397.

[11] N. Dacheux, N. Clavier, G. Wallez, V. Brandel, J. Emery, M. Quarton, M.Genet, Mat. Res. Bull. 40 (2005) 2225.

[12] G. Wallez, N. Clavier, N. Dacheux, M. Quarton, W. Van Beek, Inorg. Chem. (2006), submitted.

[13] J.F. Ziegler, JP. Biersack, U. Littmark. In: Ziegler JF, Editor. The Stopping and Range of Ions in solids, Vol.1. New York: Pergamon 1985.

[14] A. Meldrum, L.M. Wang, R.C. Ewing, Nucl. Instrum. and Meth. B 116 (1996) 220.

[15] C. Tamain, PhD thesis, Université Paris-Sud-11, IPNO-T-05-09, 2005.

[16] P. Scherrer, Gött. Nachr. 2 (1918) 98.

[17] J. Verstraete, L. Khouchaf, D. Bulteel, E. Garcia-Diaz, A.M. Flank, M.H. Tuilier, Cement and Concrete Research 34 (2004) 581.

[18] W.J. Weber, Nucl. Instrum. Meth. B 166 (2000) 98.

[19] M. Evain, U-Fit Program, Institut des Matériaux de Nantes, France, 1992.

[20] A. Benyagoub, S. Klaumünzer, Radiat. Eff. Defects in Solids 126 (1993) 105. 